(1)

\title{
Reciprocal regulation of insulin and plasma 5'-AMP in glucose homeostasis in mice
}

\author{
Lin Xia*, Zhongqiu Wang ${ }^{1, *}$, Ying Zhang ${ }^{2}$, Xiao Yang, Yibei Zhan, Rui Cheng, \\ Shiming Wang and Jianfa Zhang
}

\author{
Center for Molecular Metabolism, Nanjing University of Science and Technology, B508, \#364, 200 Xiaolingwei \\ Street, Nanjing 210094, China \\ ${ }^{1}$ Department of Radiology, Nanjing University of Chinese Medicine, Nanjing 210000, China \\ ${ }^{2}$ Department of Biochemistry and Molecular Biology, Jiangsu University School of Medicine, Zhenjiang 212013, \\ China \\ *(L Xia and Z Wang contributed equally to this work)
}

\author{
Correspondence \\ should be addressed \\ to J Zhang \\ Email \\ jfzhang@mail.njust.edu.cn
}

\begin{abstract}
A previous investigation has demonstrated that plasma $5^{\prime}$-AMP (pAMP) exacerbates and causes hyperglycemia in diabetic mice. However, the crosstalk between pAMP and insulin signaling to regulate glucose homeostasis has not been investigated in depth. In this study, we showed that the blood glucose level was more dependent on the ratio of insulin to PAMP than on the absolute level of these two factors. Administration of $5^{\prime}$-AMP significantly attenuated the insulin-stimulated insulin receptor (IR) autophosphorylation in the liver and muscle tissues, resulting in the inhibition of downstream AKT phosphorylation. A docking analysis indicated that adenosine was a potential inhibitor of IR tyrosine kinase. Moreover, the 5'-AMP treatment elevated the ATP level in the pancreas and in the isolated islets, stimulating insulin secretion and increasing the plasma level of insulin. The insulin administration decreased the $5^{\prime}$-AMP-induced hyper-adenosine level by the up-regulation of adenosine kinase activities. Our results indicate that blood glucose homeostasis is

reciprocally regulated by PAMP and insulin.
\end{abstract}

Journal of Endocrinology

(2015) 224, 225-234

\section{Introduction}

Type 2 diabetes mellitus is a complex, multisystem disease with a pathophysiology that includes defects in insulinstimulated peripheral glucose disposal and an impaired suppression of hepatic glucose production (Matthaei et al. 2000). Insulin is an essential regulator of intermediary metabolism, and insulin signaling involves a cascade of events initiated by the binding of insulin to insulin receptor (IR) followed by receptor autophosphorylation and activation of receptor tyrosine kinases, which results in tyrosine phosphorylation of the IR substrates (IRSs), including IRS1, IRS2, and IRS3 (Choi \& Kim 2010). Binding of the IRSs to the regulatory subunit of phosphoinositide 3-kinase (PI3K) results in the activation of PI3K, and the PI3K/AKT pathway is a key regulator of insulin signaling (Whiteman et al. 2002). In adipose and muscle cells, AKT (AKT1) overexpression results in an increased insulin-sensitive glucose transporter GLUT4 translocation and glucose uptake (Kohn et al. 1996, Wang et al. 1999). PI3K/AKT signaling also relays IR signals to suppress gluconeogenesis by regulating the gene expression of important enzymes via the phosphorylation-dependent regulation of the Forkhead transcription factor $\mathrm{O} 1$ and 
the PPAR $\gamma$ co-activator $1 \alpha$ (PGC1 $\alpha$ ) (Yoon et al. 2001, Puigserver et al. 2003, Li et al. 2007). In diabetic $d b / d b$ mice, insulin-stimulated AKT-Ser ${ }^{47}$ phosphorylation decreased in the muscle and adipose tissue (Shao et al. 2000).

Protein tyrosine phosphatases (PTPs) play a key role in the regulation of reversible tyrosine phosphorylation in the insulin action pathway. Under normal physiological conditions, the phosphorylation of tyrosyl residues on all of the signaling molecules is controlled with a balanced activity between the tyrosine kinases and phosphatases. Tyrosine phosphorylation is the key activator of the IR and IRS proteins, but it is easily reversed either directly or indirectly by the PTPs, such as leukocyte common antigen-related (LAR) phosphatase, PTP1B, 2-SH2domain-containing protein tyrosine phosphatase 1 (SHP1), and SHP2 (Xu et al. 2014). The general reduction in LAR or PTP1B activity enhances insulin-stimulated IR autophosphorylation and downstream substrate activation and signaling (Kulas et al. 1995, Egawa et al. 2001). The ability of vanadium compounds to inhibit PTPs has been widely used to elucidate the mechanisms of insulin action (Bernier et al. 1988, Posner et al. 1994), and the effect of vanadate $/ \mathrm{H}_{2} \mathrm{O}_{2}$ (peroxovanadate $(\mathrm{PV})$ ) as an inhibitor of PTPs has been reported in a number of studies (Heffetz et al. 1992, Ruff et al. 1997).

The insulin signaling pathway is activated when nutrients are available, whereas the AMP-activated protein kinase (AMPK) pathway is activated when cells are starved for a carbon source (Hardie 2005). The increase in AMPK activity results in the stimulation of glucose uptake in muscle, fatty acid oxidation, and inhibition of hepatic glucose production, cholesterol and triglyceride synthesis, and lipogenesis (Winder \& Hardie 1999, Ruderman et al. 2003). The AMPK system acts as a sensor for cellular energy status and is activated by increases in the cellular 5'-AMP and decreases in ATP (Hardie et al. 1998). In contrast to insulin, glucagon generally elevates glucose levels in the blood by promoting gluconeogenesis and glycogenolysis. The binding of glucagon to its receptor on the hepatocyte plasma membrane leads to activation of adenylate cyclase, and the production of cAMP increases the hepatic glucose output (Jiang \& Zhang 2003). It has been recognized that molecules containing an adenine moiety bind to adenylate cyclase and inhibit its activity (Fain et al. 1972).

In our previous study, the elevation in the level of plasma $5^{\prime}$-AMP (pAMP) is a potential upstream regulator of hyperglycemia in type 2 diabetes (Zhang et al. 2012). The question as to whether a crosstalk exists between insulin signaling and pAMP remains unknown. In this study, we demonstrate that the blood glucose level is dependent on the ratio of insulin to 5'-AMP. Exogenous 5'-AMP stimulated insulin release and inhibited the insulin signaling pathway via reducing IR autophosphorylation. Moreover, insulin decreased the $5^{\prime}$-AMP-induced hyper-adenosine level. Our results indicate that a reciprocal regulation of insulin and pAMP maintains glucose homeostasis.

\section{Materials and methods}

\section{Animals, antibodies, and chemicals}

Male C57BL/6J mice (Comparative Medicine Center, Yangzhou University, China) that were 7-8 weeks old were used in this study. The animals were maintained under $12 \mathrm{~h}$ light: $12 \mathrm{~h}$ darkness cycles with the light on at $0700 \mathrm{~h}$ and off at $1900 \mathrm{~h}$ and were given food and water ad libitum. All of the animal care and use procedures were in accordance with the guidelines provided by the Institutional Animal Care and Use Committee at the Nanjing University of Science and Technology. The antiIR- $\beta$ (\#3025), anti-phospho-tyrosine (P-Tyr-100) (\#9411), anti-AKT (\#9272), and anti-phospho-AKT (Ser-473) (\#4060) antibodies were obtained from Cell Signaling Technology (Beverly, MA, USA). Adenosine, 5'-AMP, ATP, ADP, insulin, and SQ22536 were purchased from Sigma.

\section{Treatment with $5^{\prime}$-AMP, insulin, and PV}

The indicated doses of 5'-AMP or insulin were administered to mice by i.p. injection. The same volume of saline was injected as a control. All of the injections were administered at $0900 \mathrm{~h}$, unless otherwise indicated. After injection, mice were maintained for the desired length of time. The adenylate cyclase inhibitor SQ22536 (10 mg/kg, s.c.) was administered $30 \mathrm{~min}$ before the administration of 5'-AMP. Mice were killed by cervical dislocation. Blood was collected from the carotid arteries in anticoagulant tubes containing a stop solution $(0.2 \mathrm{mmol} / \mathrm{l}$ dipyridamole, $5 \mathrm{mmol} / \mathrm{l}$ erythro-9-(2-hydroxy-3-nonyl)-adenine (EHNA), and $4.2 \mathrm{mmol} / \mathrm{l} \mathrm{EDTA),} \mathrm{and} \mathrm{then} \mathrm{the} \mathrm{liver,} \mathrm{muscle,}$ and pancreas were removed and freeze clamped in liquid nitrogen. The blood samples were immediately centrifuged at $5000 \mathrm{~g}$ for $5 \mathrm{~min}$ at $20^{\circ} \mathrm{C}$. The plasma samples obtained were then stored on ice and immediately used in the experiments. The PV solution was prepared and administered to mice as described previously (Ruff et al. 1997). Briefly, a $5 \mathrm{mM}$ solution of sodium vanadate was prepared by heating to boiling (until translucent), and the $\mathrm{pH}$ was readjusted to $\mathrm{pH} 10$. Fifteen minutes before use, $30 \% \mathrm{H}_{2} \mathrm{O}_{2}$ was added at room temperature to a final concentration of

Published by Bioscientifica Ltd 
$50 \mathrm{mM}$. The PV solutions were injected intraperitoneally into mice at a dose of $10 \mu \mathrm{l} / \mathrm{g}$ body weight. Twenty minutes after the PV injection, mice were treated with $5^{\prime}$-AMP. Mice were killed by cervical dislocation $30 \mathrm{~min}$ after the $5 '$-AMP injection, and then the liver tissues were removed and freeze clamped in liquid nitrogen.

\section{Immunoprecipitation, western blotting, and IR autophosphorylation analysis}

Immunoprecipitation and a western blot assay were performed as described previously (Kruszynska et al. 2002). The lysates and immunoprecipitates were resolved by SDS-PAGE, and the proteins were detected by immunoblotting. For the IR autophosphorylation analysis, the liver protein was isolated using cold lysis buffer (Endemann et al. 1990). The lysate was incubated for $10 \mathrm{~min}$ at room temperature with insulin $(2.5 \mathrm{nM})$ and the indicated doses of adenosine in a $1 \mathrm{ml}$ reaction mixture containing the following: $50 \mathrm{mM}$ HEPES, $\mathrm{pH}$ 7.6, $1 \mathrm{mM}$ dithiothreitol, $10 \mathrm{mM} \mathrm{MgCl} 2,3 \mathrm{mM} \mathrm{MnCl}, 0.1 \%$ Triton X-100, and $50 \mu \mathrm{M}$ ATP. The reaction was stopped by the addition of EDTA to a final concentration of $67 \mathrm{mM}$ (Stephens et al. 1997). The reaction mixture was analyzed by immunoprecipitation and a western blot assay. The quantification of the bands was performed by the Gel Analysis V2.02 Software (Clin Science Instruments, Shanghai, China).

\section{Docking analysis}

The 3D structure of the IR was obtained from the Protein Database (PDB ID: 1IR3). The mol2 files of ATP (18456332) and adenosine (895113) were obtained from the ZINC database. The binding of the IR tyrosine kinase with ATP and adenosine was studied using the AutoDock 4.2 docking software. The essential hydrogen atoms and the Kollman charges were added. The grid was centered in the active site region, and the grid maps were generated using the Autogrid program. The docking simulations were performed by the Lamarckian Genetic Algorithm. The result of each docking experiment was derived from 100 different runs that were set to terminate after a maximum of 2500000 energy evaluations.

\section{Islet preparation and culture conditions}

Pancreatic islets were isolated by the collagenase method (Kaiser et al. 1988). After $48 \mathrm{~h}$ of culture in RPMI 1640 containing antibiotics $(100 \mathrm{U} / \mathrm{ml}$ penicillin and $100 \mathrm{ng} / \mathrm{ml}$ streptomycin) and $10 \%$ fetal bovine serum, groups of ten isolated islets were preincubated for $60 \mathrm{~min}$ in the basal medium. The islets then were incubated in the basal medium, either with or without the addition of $10 \mathrm{mM}$ 5 '-AMP. The basal medium was the Krebs-Ringer bicarbonate buffer containing $5 \mathrm{mM}$ pyruvate, $5 \mathrm{mM}$ glutamate, $5 \mathrm{mM}$ fumarate, $3.3 \mathrm{mM}$ glucose, and $400 \mathrm{mg} / 100 \mathrm{ml}$ BSA and was equilibrated with $95 \% \mathrm{O}_{2}-5 \% \mathrm{CO}_{2}$. All of the incubations were carried out at $37^{\circ} \mathrm{C}$ for $60 \mathrm{~min}$. At the end of the incubations, aliquots of the incubation media were removed for the insulin assay.

\section{Analysis of adenosine, and nucleotide and adenosine kinase activities}

Adenosine and nucleotides were extracted from frozen samples using $0.4 \mathrm{~N}$ perchloric acid and analyzed by reverse-phase HPLC (Waters 1525 System; Millipore Corp., Bedford, MA, USA), according to the procedure described previously (Zhang et al. 2012). For the isolated pancreatic islets, low concentrations of ATP were assessed using a luminometric method, as described previously (Detimary et al. 1996). To assay adenosine kinase (ADK) activities, the liver tissue was homogenized in $50 \mathrm{mM}$ Tris- $\mathrm{HCl}$ buffer (pH 7.4) containing $3 \mathrm{mM} \mathrm{MgCl}_{2}, 150 \mathrm{mM}$ $\mathrm{KCl}$, and $0.2 \mathrm{mM}$ phenylmethylsulphonyl fluoride. The homogenate was centrifuged at $50000 \boldsymbol{g}$ for $20 \mathrm{~min}$ at $4{ }^{\circ} \mathrm{C}$, and the supernatant was stored at $-20^{\circ} \mathrm{C}$. The ADK activities were assayed as described previously (Ward et al. 1998). Approximately $20 \mu \mathrm{g}$ supernatant was incubated for $5 \mathrm{~min}$ at $37{ }^{\circ} \mathrm{C}$ with a reaction mixture containing $20 \mathrm{mM}$ Tris maleate buffer ( $\mathrm{pH} 5.75$ ) containing $0.5 \mathrm{mM}$ $\mathrm{MgCl}_{2}, 0.15 \mathrm{mM}$ EHNA, $0.5 \mathrm{mM}$ ATP, $1 \mathrm{mM}$ dithiothreitol and $50 \mu \mathrm{M}$ adenosine in a total volume of $80 \mu \mathrm{l}$. The reaction product AMP was measured by HPLC.

\section{RNA extraction and quantitative real-time RT-PCR}

RNA extraction and qPCR were performed as described previously (Zhang et al. 2012). The following primers were used: Adk: 5'-GCCCACCATGGTTCTCATTA-3' (forward), 5'-CCTGCATTGGAAGCAGAAAT-3' (reverse) and Actb 5'-GATCATTGCTCCTCCTGAGC-3' (forward), 5'-ACTCCTGCTTGCTGATCCAC-3' (reverse).

\section{Blood glucose and insulin measurements}

Blood glucose was determined using a One Touch Blood Glucose Meter (AW063-436-01A; LifeScan, Inc., Milpitas, California, USA) with $3 \mu$ l of whole blood obtained by tail

Published by Bioscientifica Ltd. 

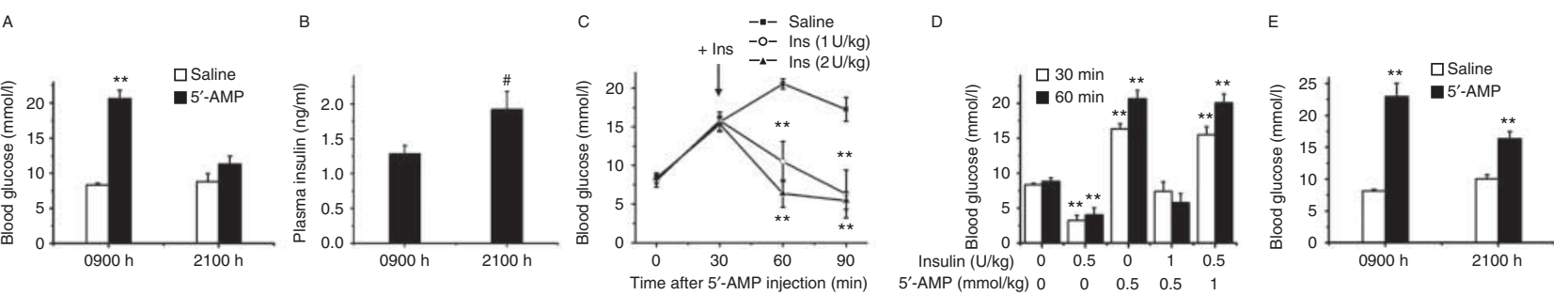

Figure 1

Regulation of blood glucose by $5^{\prime}$-AMP and insulin. (A) Freely fed mice were treated with a low dose of $5^{\prime}$-AMP $(0.5 \mathrm{mmol} / \mathrm{kg})$ by i.p. injection at $0900 \mathrm{~h}$ and at $2100 \mathrm{~h}$ respectively. Blood glucose levels were measured at $1 \mathrm{~h}$ after $5^{\prime}$-AMP injection. (B) Plasma insulin was measured at $0900 \mathrm{~h}$ and at $2100 \mathrm{~h}$ respectively. (C) The effect of exogenous insulin on $5^{\prime}$-AMP-induced hyperglycemia. Mice were treated intraperitoneally with insulin (Ins)

bleed. Plasma insulin concentrations were determined by ${ }^{125}$ I RIA Kits (Linco Research, Inc., St Louis, MO, USA).

\section{Statistical analyses}

Data were expressed as mean \pm s.E.M. Statistical analysis was performed by one-way ANOVA, using Tukey's post hoc test and Student's $t$-test. Significance was defined as $P<0.05$.

\section{Results}

\section{The blood glucose level was controlled by the ratio of insulin to $5^{\prime}$-AMP}

Our previous study had demonstrated that pAMP is an upstream regulator of hyperglycemia in diabetes, and exogenous 5'-AMP increases the intracellular adenosine
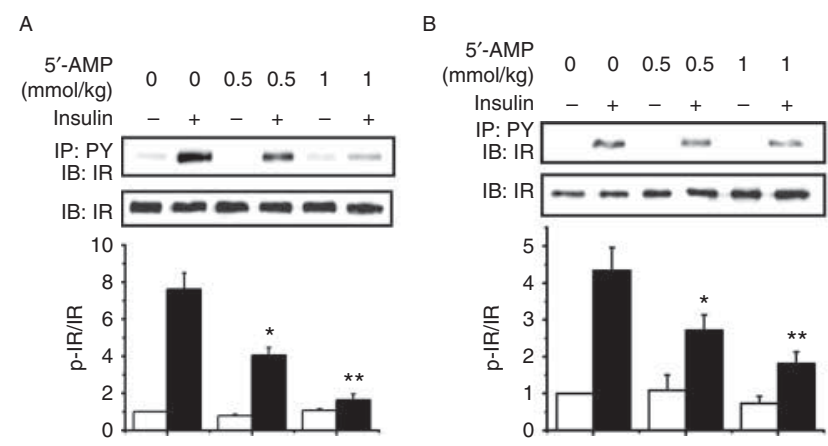

\section{Figure 2}

Effects of $5^{\prime}$-AMP on insulin signaling in the liver and skeletal muscle. Fasted mice were treated with insulin and $5^{\prime}$-AMP, and at 10 min after treatment, the liver and the muscle tissue samples were collected. ( $A$ and $B$ ) Insulin receptor (IR) phosphorylation in the liver and the muscle respectively. Protein extracts were subjected to immunoprecipitation with the anti-phospho-tyrosine antibody. The immunoprecipitates were analyzed by western blot with the anti-IR- $\beta$ antibody. (C and D) AKT
$30 \mathrm{~min}$ after injection of $5^{\prime}$-AMP $(0.5 \mathrm{mmol} / \mathrm{kg})$. (D) Different responses of blood glucose by i.p. injection of fed mice with various doses of $5^{\prime}$-AMP and insulin. (E) Similar experiments as in (A), but i.p. injection with a high dose of $5^{\prime}$-AMP $(1 \mathrm{mmol} / \mathrm{kg})$. Data are expressed as means \pm S.E.M. of four animals. ${ }^{* *} P<0.01$ compared with saline control. ${ }^{*} P<0.05$ compared with at $0900 \mathrm{~h}$.

level and causes hyperglycemia in WT mice (Zhang et al. 2012). The blood glucose and insulin concentration have a daily variation rhythm with a pronounced night peak during feeding time (Ando et al. 2005, Takahashi et al. 2012). To investigate whether the daily variations of glucose and insulin affect the 5'-AMP-induced hyperglycemia, 5'-AMP $(0.5 \mathrm{mmol} / \mathrm{kg})$ was administered to freely fed mice by i.p. injection during the daytime (0900 h) and nighttime $(2100 \mathrm{~h})$. At these two time points, similar high glycogen levels were observed in the mice liver (Roesler \& Khandelwal 1985). As shown in Fig. 1A, the $5^{\prime}$-AMP injection caused hyperglycemia (over $20 \mathrm{mmol} / \mathrm{l}$ blood glucose) at $0900 \mathrm{~h}$, and the same dose of $5^{\prime}$-AMP failed to significantly elevate the blood glucose level at $2100 \mathrm{~h}$. A subsequent measurement of the plasma insulin level indicated that the insulin level at $2100 \mathrm{~h}$ was higher than that at $0900 \mathrm{~h}$ (Fig. 1B). Figure $1 \mathrm{C}$ shows that the

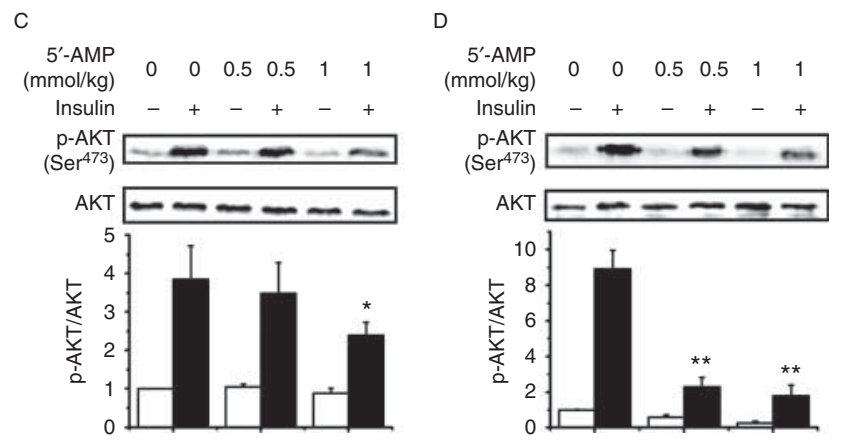

phosphorylation in the liver and muscle respectively. Protein extracts were analyzed by western blot with the anti-AKT and anti-phospho-AKT (Ser-473) antibodies. The bar graph shows the degree of phosphorylation. The group receiving no stimulation without $5^{\prime}$-AMP was set at 1 . Values were expressed as means \pm S.E.M. from three independent experiments. $* P<0.05$ and $* * P<0.01$ compared with the group receiving insulin stimulation without $5^{\prime}$-AMP treatment.

Published by Bioscientifica Ltd. 
exogenous insulin reduced the $5^{\prime}$-AMP-induced hyperglycemia in $30 \mathrm{~min}$ after the $5^{\prime}$-AMP injection. Then, the mixed dose of $5^{\prime}$-AMP and insulin was injected into mice, and we found that the absolute level of insulin or pAMP was apparently of less significance than the ratio of these two factors in regulating the blood glucose level (Fig. 1D). A high dose of 5'-AMP (1 mmol/kg) was injected into mice, and the blood glucose level significantly increased at $0900 \mathrm{~h}$ and at $2100 \mathrm{~h}$ (Fig. 1E). These results suggested that the ratio of insulin to $5^{\prime}$-AMP maintains the glucose homeostasis.

\section{5'-AMP suppressed the insulin-stimulated phosphorylation in the liver and muscle}

To clarify the effect of $5^{\prime}$-AMP on the action of insulin, mice that had been fasting were injected with insulin and different doses of $5^{\prime}$-AMP. The results indicated that 5'-AMP caused a dose-dependent inhibition of insulinstimulated IR tyrosine phosphorylation in the liver and the skeletal muscle tissues (Fig. 2A and B). The maximal tyrosine phosphorylation decreased by $79 \%(P<0.01)$ and $58 \%(P<0.01)$ in the liver and muscle tissue respectively.
Then, we determined whether the phosphorylation of AKT, which is a downstream target of the IR, changed in response to $5^{\prime}$-AMP. $5^{\prime}$-AMP also caused a dose-dependent inhibition of insulin-stimulated AKT phosphorylation, and the maximal AKT-Ser ${ }^{473}$ phosphorylation decreased by $46 \%(P<0.05)$ and $80 \%(P<0.01)$ in the liver and muscle tissue respectively (Fig. $2 \mathrm{C}$ and $\mathrm{D}$ ).

\section{Competition of adenosine and ATP for the ATP-binding site on the IR tyrosine kinase}

cAMP plays a key role in the regulation of gluconeogenesis and glycogenolysis (Exton \& Park 1968). To investigate whether the 5'-AMP-induced hyperglycemia occurs through the cAMP pathway, 5'-AMP-treated mice were given the adenylate cyclase inhibitor SQ22536. Figure 3A shows that SQ22536 failed to decrease the 5'-AMP-induced hyperglycemia, indicating that 5'-AMPinduced hyperglycemia was not dependent on the cAMP pathway. pAMP-induced hyperglycemia is not directly related to the adenosine receptor pathways, although administration of 5'-AMP causes a significant increase in the hepatic adenosine level (Zhang et al. 2012).

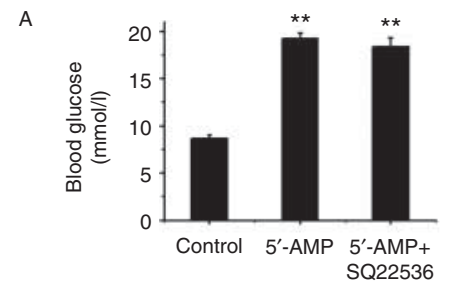

D

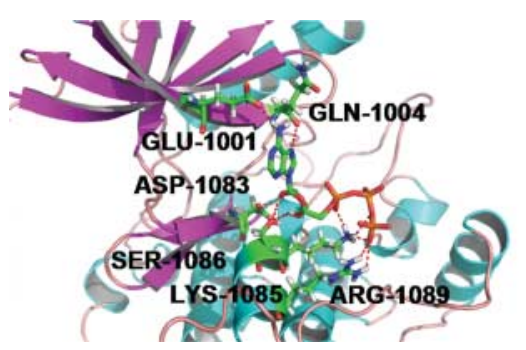

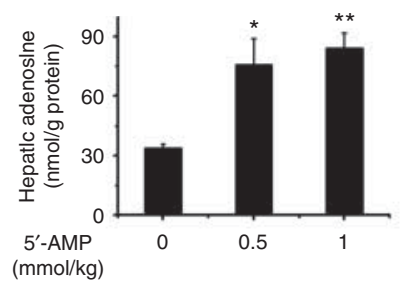

$E$

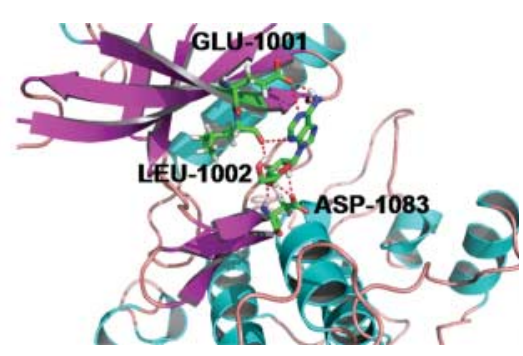

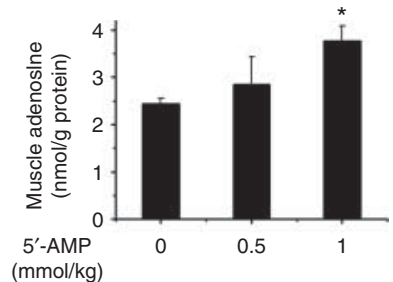

$\mathrm{F}$

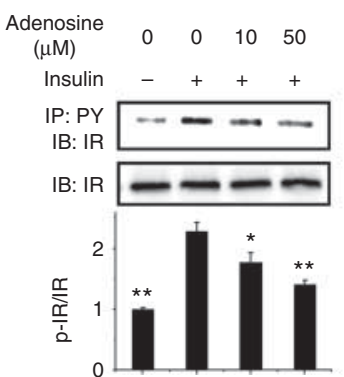

\section{Figure 3}

Effects of adenosine on insulin receptor autophosphorylation. (A) Freely fed mice were treated with $5^{\prime}$-AMP $(0.5 \mathrm{mmol} / \mathrm{kg})$ by i.p. injection at $0900 \mathrm{~h}$. Blood glucose levels were measured at $1 \mathrm{~h}$ after $5^{\prime}$-AMP injection. The adenylate cyclase inhibitor SQ22536 (10 mg/kg, s.c.) was administered 30 min before $5^{\prime}$-AMP. HPLC analysis for adenosine levels in the liver (B) and the muscle $(C)$ of fasted mice at $10 \mathrm{~min}$ after various doses of $5^{\prime}$-AMP injection. Values are expressed as means \pm s.E.M. of four animals. ${ }^{\star} P<0.05$ and $* * P<0.01$ compared with saline control. Docking analysis of adenosine and ATP. The docked complexes are ATP and adenosine in (D) and (E) respectively. Hydrogen bonds were indicated by red dash lines. (F) Adenosine inhibits IR autophosphorylation in vitro. The reaction was performed as described under 'Materials and methods' section. The final results were determined by immunoprecipitation and western blotting. The bar graph shows the degree of phosphorylation. The control was set at 1. Values are expressed as means \pm S.E.M. from three independent experiments. ${ }^{*} P<0.05$ and $* * P<0.01$ compared with the group receiving insulin stimulation without adenosine. http://joe.endocrinology-journals.org DOI: 10.1530/JOE-14-0501
() 2015 Society for Endocrinology Printed in Great Britain 
Table 1 Results of docking analysis

\begin{tabular}{l|ccc}
\hline Compound & $\begin{array}{c}\text { Free energy of } \\
\text { binding }(\mathrm{kcal} / \mathrm{mol})\end{array}$ & $\begin{array}{c}\text { Intermolecular } \\
\text { energy }\end{array}$ \\
\cline { 1 - 1 } ATP & -2.60 & -5.88 \\
Adenosine & -3.61 & -5.4 \\
\hline
\end{tabular}

\begin{tabular}{c}
\hline $\begin{array}{c}\text { Total internal } \\
\text { energy }\end{array}$ \\
\hline 12.53 \\
-2.46 \\
\hline
\end{tabular}

\begin{tabular}{c}
\hline $\begin{array}{c}\text { Torsional } \\
\text { free energy }\end{array}$ \\
\hline 3.28 \\
1.79 \\
\hline
\end{tabular}

\begin{tabular}{c}
\hline $\begin{array}{c}\text { Inhibition } \\
\text { constant }\end{array}$ \\
\hline 12.46 \\
2.27 \\
\hline
\end{tabular}

Similarly, at $10 \mathrm{~min}$ after the $5^{\prime}$-AMP injection, the levels of adenosine were acutely increased in the liver and muscle tissues of the fasting mice (Fig. 3B and C). We hypothesized that the intracellular hyper-adenosine and ATP were in competition for the ATP-binding site on tyrosine kinase, leading to the reduction in the insulin-stimulated IR autophosphorylation. The docking analysis of adenosine and ATP was performed by Autodock 4.2 and Pymol 1.4. Figure 3D and E show the interaction of the IR tyrosine kinase with ATP and adenosine respectively. ATP was found to interact with Glu-1001, Gln-1004, Asp-1083, Lys-1085, Ser-1086, and Arg-1089, and adenosine was found to interact with Glu-1001, Leu-1002, and Asp-1083. The docking results of the interaction are given in Table 1 . The binding energy value of adenosine from Autodock $4.2 \mathrm{was}-3.61 \mathrm{kcal} / \mathrm{mol}$, which was lower than that of ATP $(-2.6 \mathrm{kcal} / \mathrm{mol})$. The docking results could predict that adenosine was a stronger binding ligand with the IR. The in vitro experiments revealed that adenosine caused a dose-dependent inhibition of the insulin-stimulated IR autophosphorylation (Fig. 3F). Adenosine at concentrations of 10 and $50 \mu \mathrm{M}$ reduced the autophosphorylation by $22 \%(P<0.05)$ and $38 \%(P<0.01)$ respectively. These results implied that
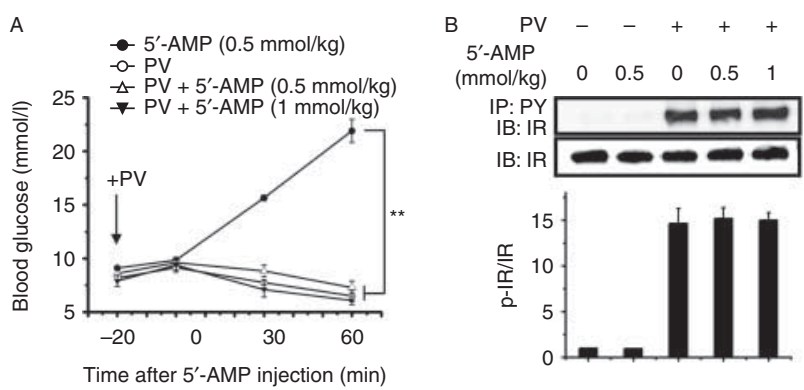

Figure 4

5'-AMP failed to cause hyperglycemia in peroxovanadate (PV)-treated mice. (A) At 20 min after administration of PV by i.p. injection, mice were treated with $5^{\prime}$-AMP. Then, blood glucose was measured. Data are expressed as means \pm S.E.M. of four animals. $* * P<0.01$ compared with administration of $5^{\prime}$-AMP. (B) The liver tissue samples were obtained $30 \mathrm{~min}$ after i.p. injection of $5^{\prime}$-AMP. Protein extracts were subjected to immunoprecipitation with the anti-phospho-tyrosine antibody. The immunoprecipitates were analyzed by western blot with the anti-IR- $\beta$ the elevated adenosine could dock onto the ATP-binding site of the IR, leading to the inhibition of the ability to autophosphorylate and phosphorylate intracellular substrates.

\section{$5^{\prime}$-AMP did not elevate the blood glucose level in the PV-treated mice}

The PTPs play a crucial role in the development of insulin resistance in classic metabolic tissues by inhibiting the activation of several molecules in the insulin signaling cascade (Xu et al. 2014). PV is an inhibitor of the PTPs and is a potent insulin mimicker (Fantus et al. 1989, Heffetz et al. 1992), which has been shown to increase the level of the IR phosphorylation (Ruff et al. 1997). To investigate whether PV can overcome the 5'-AMP-induced hyperglycemia, mice were given PV by i.p. injection, and after $20 \mathrm{~min}$, mice were treated with different doses of $5^{\prime}$-AMP. Figure $4 \mathrm{~A}$ shows that neither the high dose $(1 \mathrm{mmol} / \mathrm{kg})$ nor the low dose $(0.5 \mathrm{mmol} / \mathrm{kg})$ of $5^{\prime}$-AMP caused hyperglycemia in the PV-treated mice. The PV treatment increased the tyrosine phosphorylation of the IR, which was unaltered by the high and low doses of $5^{\prime}$-AMP (Fig. 4B), and the PV-induced phosphorylation of AKT was
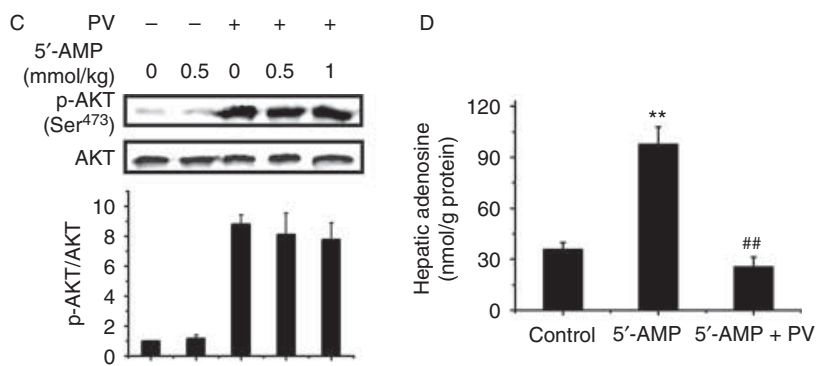

antibody. (C) Protein extracts were analyzed by western blot with the antiAKT and anti-phospho-AKT (Ser-473) antibodies. The bar graph shows the degree of phosphorylation. The group without administration of PV and $5^{\prime}$-AMP was set at 1 . Values are expressed as means \pm s.E.M. from three independent experiments. (D) HPLC analysis for hepatic adenosine level at $30 \mathrm{~min}$ after i.p. injection of $5^{\prime}$-AMP $(0.5 \mathrm{mmol} / \mathrm{kg})$. Data are expressed as means \pm s.E.M. of four animals. ${ }^{*} P<<0.01$ compared with saline control. ${ }^{\# \#} P<0.01$ compared with $5^{\prime}$-AMP treatment.

Published by Bioscientifica Ltd. 

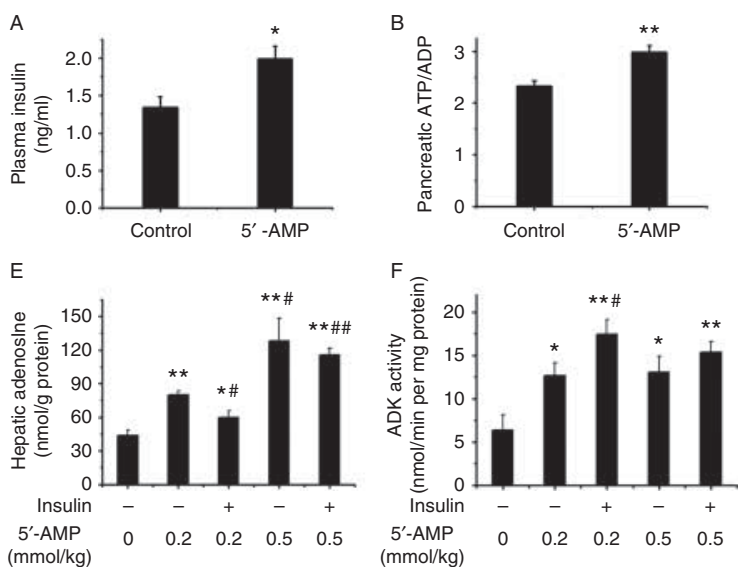
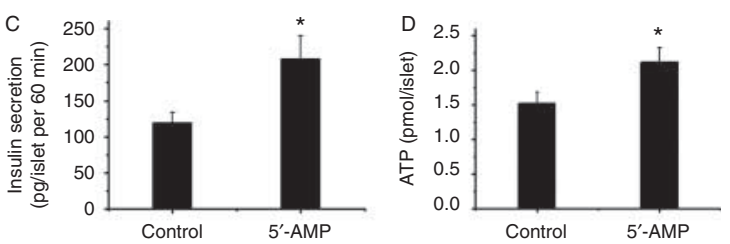

G

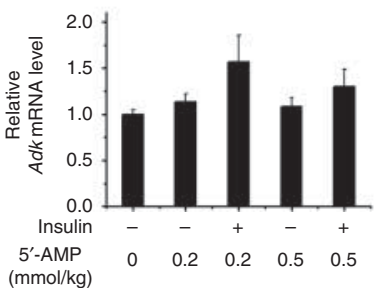

Figure 5

5'-AMP stimulated insulin secretion and insulin decreased 5 '-AMP-induced hyper-adenosine level. The analysis for plasma insulin (A) and ATP/ADP ratio in pancreas (B) at $1 \mathrm{~h}$ after i.p. injection of $5^{\prime}$-AMP $(0.5 \mathrm{mmol} / \mathrm{kg})$. Data are expressed as means \pm s.E.M. of four animals. ${ }^{*} P<0.05$ and $* * P<0.01$ compared with saline control. Pancreatic islets were incubated with or without $10 \mathrm{mM} \mathrm{5'-AMP} \mathrm{for} 60 \mathrm{~min}$. Insulin secretion (C) and ATP content (D) were assessed. Data are expressed as means \pm s.E.M. of three separate experiments. ${ }^{\star} P<0.05$ compared with saline control. (E) HPLC analysis for

also unchanged (Fig. 4C). The HPLC analysis revealed that PV significantly decreased the cellular adenosine level in the $5^{\prime}$-AMP-treated mice (Fig. 4D).

\section{5'-AMP increased the plasma insulin level and insulin decreased the 5'-AMP-induced hyper-adenosine level}

The previous observations revealed that 5'-AMP blocked the insulin signaling and caused hyperglycemia. Then, we tested whether the 5'-AMP injection induced the change in the plasma insulin level. Figure $5 \mathrm{~A}$ shows that $1 \mathrm{~h}$ after the $5^{\prime}$-AMP injection, the plasma insulin level increased by $50 \%$ compared with the saline control. The ATP/ADP ratio, which regulates the insulin secretion, also increased in the pancreatic tissues (Fig. 5B). Similarly, while the isolated islets were exposed for $60 \mathrm{~min}$ to $5^{\prime}$-AMP, the insulin release increased compared with the saline control (Fig. 5C). The ATP level in the islets also increased (Fig. 5D). Then, we investigated the effect of insulin on the intracellular adenosine concentration. For the high dosage of $0.5 \mathrm{mmol} / \mathrm{kg} \mathrm{5}$-AMP, the insulin injection only resulted in a decreasing tendency, whereas for mice treated with $0.2 \mathrm{mmol} / \mathrm{kg} 5^{\prime}$-AMP, the insulin injection significantly decreased the 5'-AMP-induced hyperadenosine level in the liver (Fig. 5E), which was associated with an increase in the enzymatic activities of ADK (Fig. 5F). Insulin failed to significantly enhance the hepatic adenosine level at 20 min after i.p. injection of a mixture of $5^{\prime}$-AMP and insulin $(1 \mathrm{U} / \mathrm{kg})$. (F) Mice were treated with a mixture of $5^{\prime}$-AMP and insulin $(1 \mathrm{U} / \mathrm{kg})$, and the activity of ADK in the cytosol of livers was assayed. (G) The mRNA expression of $A d k$ in the livers. Data are expressed as means \pm S.E.M. of four animals. $* P<0.05$ and $* * P<0.01$ compared with saline control. ${ }^{\#} P<0.05$ and ${ }^{\# \#} P<0.01$ compared with administration of $5^{\prime}$-AMP $(0.2 \mathrm{mmol} / \mathrm{kg})$.

expression of the $A d k$ mRNA with a high or low dosage of the $5^{\prime}$-AMP treatment (Fig. 5G).

\section{Discussion}

Glucose homeostasis is under a complex and only partially understood neuro-hormonal regulation. Among the hormonal factors, insulin is the primary hormone that lowers the blood glucose by inhibiting glucose production and stimulating glucose utilization in insulin-sensitive tissues, whereas glucagon and glucocorticoids are the major hormones that can increase the plasma glucose concentrations (DeFronzo 1988, Gerich 1993). Endothelial cell damage of the veins caused by FFA elevated the pAMP levels in the $d b / d b$ diabetic mice, and mice treated with 5'-AMP showed induced hyperglycemia and displayed patterns similar to the $d b / d b$ mice in several glucose metabolic gene expressions and physiological responses (Zhang et al. 2012). In this study, we demonstrated that $5^{\prime}$-AMP, as a counter-regulatory factor of insulin, impairs the insulin signaling and elevates the blood glucose level. The ratio of 5'-AMP to insulin controls the blood glucose level. The plasma insulin concentration had a daily variation and a peak at nighttime (Ando et al. 2005), which resulted in different changes in the blood glucose after the $5^{\prime}$-AMP treatment in the daytime and in the nighttime. The finding that $5^{\prime}$-AMP impaired the insulin

Published by Bioscientifica Ltd 
action implied that $5^{\prime}$-AMP was a primary factor causing insulin resistance in type 2 diabetes.

Extracellular 5'-AMP (including pAMP) cannot be directly transferred into intracellular $5^{\prime}$-AMP. At the early stage of the $5^{\prime}$-AMP injection, the intracellular $5^{\prime}$-AMP failed to increase, but the intracellular adenosine sharply increased, resulting in an increase in the intracellular ATP level (Weisman et al. 1988) and decreasing the ratio of $5^{\prime}$-AMP/ATP. A decrease in the cellular ratio of 5'-AMP/ATP should lead to a decrease in the AMPK activity and glucose utilization (Hardie et al. 1998). Hyper-adenosine also enhances the activity of glucose-6-phosphatase, resulting in an increased glycogenolysis and endogenous glucose production (Zhang et al. 2012). Thus, glycogenolysis plays a key role in $5^{\prime}$-AMP-induced hyperglycemia. It is well known that the glycogen level displays a daily variation in the mouse liver with a decrease in daytime (Roesler \& Khandelwal 1985). A different injection time with 5'-AMP will cause a different increase in blood glucose, which is dependent on hepatic glycogen level in these time points (Zhang et al. 2006, 2012). In diabetic mice, pAMP and hepatic adenosine are maintained constantly at a high level; 5'-AMP injection in normal mice only results in sharply increases in pAMP and hepatic adenosine at the first stage and causes a temporary elevation in blood glucose levels. At the last stage of the $5^{\prime}$-AMP injection, the increased adenosine level is primarily phosphorylated to 5'-AMP by ADK (Arch \& Newsholme 1978); increased intracellular 5'-AMP enhances activities of AMPK and phosphofructokinase and the inhibition of the activity of fructose-1,6-bisphosphatase, resulting in an increased glucose utilization and reduced gluconeogenesis (Zhang et al. 2006). The proposed possible scheme of this regulatory event is shown in Fig. 6.

$5^{\prime}$-AMP has no influence on the affinity of insulin binding to its receptor (Zhang et al. 2012). Our results indicate that $5^{\prime}$-AMP causes a dose-dependent inhibition of the insulin-stimulated IR autophosphorylation in the liver and muscle tissues, inhibiting the activity of the receptor tyrosine kinase and suppressing the phosphorylation of downstream proteins. The docking analysis revealed that adenosine is a stronger binding ligand with the IR compared with ATP. In addition, 5'-AMP attenuated the insulin-stimulated AKT phosphorylation in the liver and muscle tissues. AKT, a serine/threonine kinase, is a downstream target of the IR, and it has been implicated as a key signaling protein for several of the actions of insulin, including activation of glycogen synthesis, protein synthesis, and GLUT4 translocation to the cell surface, thereby increasing glucose transport (Whiteman et al.

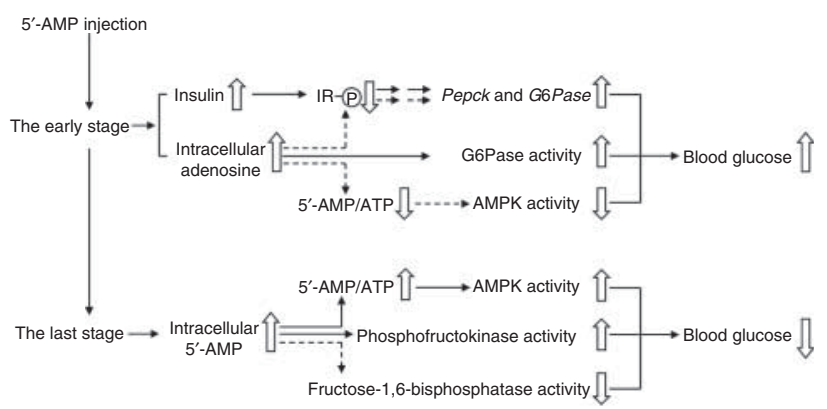

\section{Figure 6}

Schematic of the effects of $5^{\prime}$-AMP on blood glucose over time. At the early stage of $5^{\prime}$-AMP injection, the intracellular adenosine sharply increased, which impaired the action of insulin, reduced the activity of AMPK, and enhanced the activity of G6Pase, resulting in an increase in blood glucose. At the last stage of the $5^{\prime}$-AMP injection, the increased intracellular $5^{\prime}$-AMP enhanced the activities of AMPK and phosphofructokinase and the inhibition of the activity of fructose-1,6-bisphosphatase, leading to decreased blood glucose levels from high to baseline or lower. IR, insulin receptor; G6Pase, glucose-6-phosphatase; PEPCK, phosphoenolpyruvate carboxykinase. Solid line, positive regulation; Dashed line, negative regulation.

2002, Guo 2014). The decreased AKT phosphorylation is due to the reduced IR autophosphorylation and might be a result of the inhibitory activities of other upstream kinases including AKT by adenosine binding to the ATP-binding site of these kinases. In diabetic $d b / d b$ mice, insulinstimulated AKT phosphorylation in skeletal muscle decreased compared with WT mice (Shao et al. 2000). The reduced AKT activity may contribute to the cellular mechanism for the decreased GLUT4 translocation, the increased expression of the gluconeogenic genes, and the insulin resistance (Shao et al. 2000, Whiteman et al. 2002, Puigserver et al. 2003, Guo 2014). PV, an inhibitor of PTPs and a potent insulin mimicker (Fantus et al. 1989, Heffetz et al. 1992), significantly reversed the 5'-AMP-induced decrease in IR and the downstream phosphorylation of the kinases. Unexpectedly, PV significantly inhibited the $5^{\prime}$-AMP-induced hyper-adenosine in the liver. All of this evidence revealed that cellular adenosine plays a key role in the $5^{\prime}$-AMP-induced hyperglycemia.

As a second messenger, cAMP stimulates gluconeogenesis and glycogenolysis in the liver (Exton \& Park 1968). We found that $5^{\prime}$-AMP-induced hyperglycemia was not dependent on the cAMP pathway. The hyperadenosine level is the primary factor. Our results revealed that adenosine was a stronger binding ligand with the IR compared with ATP, inhibiting the insulin-stimulated receptor tyrosine phosphorylation and impairing the action of insulin. In the early stage of type 2 diabetes, a high level of insulin circulates in the blood because the

Published by Bioscientifica Ltd 
pancreas can still produce the hormone (Zhou et al. 1999). $5^{\prime}$-AMP injection not only impairs the insulin action but also stimulates the plasma insulin level, which is similar to insulin resistance. In pancreatic $\beta$ cells, ATP plays critical roles in regulating the insulin secretion. An increase in cytosolic ATP or the ATP/ADP ratio induces the closure of the ATP-sensitive potassium channel, resulting in depolarization of the plasma membrane to allow for $\mathrm{Ca}^{2+}$ influx, which triggers insulin secretion from cells (Detimary et al. 1998). 5'-AMP injection resulted in an elevation in the ATP level in the isolated islets and the pancreas, which could contribute to the stimulation of the insulin production.

In conclusion, $5^{\prime}$-AMP increases the plasma insulin level and impairs the insulin signaling via intracellular hyper-adenosine, leading to a reduction in the insulin responsiveness. Insulin decreases the level of 5'-AMPinduced hyper-adenosine in the liver. Blood glucose homeostasis is reciprocally regulated by pAMP and insulin. The present data could be useful for understanding the crucial role of pAMP in the insulin resistance of type 2 diabetes.

\section{Declaration of interest}

The authors declare that there is no conflict of interest that could be perceived as prejudicing the impartiality of the research reported.

\section{Funding}

This work was supported by the National Science Foundation of China (31171125) and the National Basic Research Program of China (2012CB517505 and 2013CB945203).

\section{References}

Ando H, Yanagihara H, Hayashi Y, Obi Y, Tsuruoka S, Takamura T, Kaneko S \& Fujimura A 2005 Rhythmic messenger ribonucleic acid expression of clock genes and adipocytokines in mouse visceral adipose tissue. Endocrinology 146 5631-5636. (doi:10.1210/en.2005-0771)

Arch JR \& Newsholme EA 1978 Activities and some properties of 5'nucleotidase, adenosine kinase and adenosine deaminase in tissues from vertebrates and invertebrates in relation to the control of the concentration and the physiological role of adenosine. Biochemical Journal 174 965-977.

Bernier M, Larid DM \& Lane MD 1988 Effect of vanadate on the cellular accumulation of pp15, an apparent product of insulin receptor tyrosine kinase action. Journal of Biological Chemistry 263 13625-13634.

Choi K \& Kim YB 2010 Molecular mechanism of insulin resistance in obesity and type 2 diabetes. Korean Journal of Internal Medicine $\mathbf{2 5}$ 119-129. (doi:10.3904/kjim.2010.25.2.119)

DeFronzo RA 1988 The triumvirate: $\beta$-cell, muscle, liver. A collusion responsible for NIDDM. Diabetes 37 667-687. (doi:10.2337/ diab.37.6.667)

Detimary P, Van den Berghe G \& Henquin JC 1996 Concentration dependence and time course of the effects of glucose on adenine and guanine nucleotides in mouse pancreatic islets. Journal of Biological Chemistry 271 20559-20565. (doi:10.1074/jbc.271.34.20559)

Detimary P, Dejonghe S, Ling Z, Pipeleers D, Schuit F \& Henquin JC 1998 The changes in adenine nucleotides measured in glucose-stimulated rodent islets occur in $\beta$ cells but not in $\alpha$ cells and are also observed in human islets. Journal of Biological Chemistry 273 33905-33908. (doi:10.1074/jbc.273.51.33905)

Egawa K, Maegawa H, Shimizu S, Morino K, Nishio Y, Bryer-Ash M, Cheung AT, Kolls JK, Kikkawa R \& Kashiwagi A 2001 Protein-tyrosine phosphatase-1B negatively regulates insulin signaling in 16 myocytes and Fao hepatoma cells. Journal of Biological Chemistry 276 10207-10211. (doi:10.1074/jbc.M009489200)

Endemann G, Yonezawa K \& Roth RA 1990 Phosphatidylinositol kinase or an associated protein is a substrate for the insulin receptor tyrosine kinase. Journal of Biological Chemistry 265 396-400.

Exton JH \& Park CR 1968 The role of cyclic AMP in the control of liver metabolism. Advances in Enzyme Regulation 6 391-407. (doi:10.1016/ 0065-2571(68)90024-1)

Fain JN, Pointer RH \& Ward WF 1972 Effects of adenosine nucleosides on adenylate cyclase, phosphodiesterase, cyclic adenosine monophosphate accumulation, and lipolysis in fat cells. Journal of Biological Chemistry 247 6866-6872.

Fantus IG, Kadota S, Deragon G, Foster B \& Posner BI 1989 Pervanadate [peroxide(s) of vanadate] mimics insulin action in rat adipocytes via activation of the insulin receptor tyrosine kinase. Biochemistry $\mathbf{2 8}$ 8864-8871. (doi:10.1021/bi00448a027)

Gerich JE 1993 Control of glycaemia. Baillière's Clinical Endocrinology and Metabolism 7 551-586.

Guo S 2014 Insulin signaling, resistance, and the metabolic syndrome: insights from mouse models into disease mechanisms. Journal of Endocrinology 220 T1-T23. (doi:10.1530/JOE-13-0327)

Hardie DG 2005 New roles for the LKB1 $\rightarrow$ AMPK pathway. Current Opinion in Cell Biology 17 167-173. (doi:10.1016/j.ceb.2005.01.006)

Hardie DG, Carling D \& Carlson M 1998 The AMP-activated/SNF1 protein kinase subfamily: metabolic sensors of the eukaryotic cell? Annual Review of Biochemistry 67 821-855. (doi:10.1146/annurev. biochem.67.1.821)

Heffetz D, Rutter WJ \& Zick Y 1992 The insulinomimetic agents $\mathrm{H}_{2} \mathrm{O}_{2}$ and vanadate stimulate tyrosine phosphorylation of potential target proteins for the insulin receptor kinase in intact cells. Biochemical Journal 288 631-635.

Jiang G \& Zhang BB 2003 Glucagon and regulation of glucose metabolism. American Journal of Physiology. Endocrinology and Metabolism 284 E671-E678. (doi:10.1152/ajpendo.00492.2002)

Kaiser N, Corcos AP, Tur-Sinai A, Ariav Y \& Cerasi E 1988 Monolayer culture of adult rat pancreatic islets on extracellular matrix: long term maintenance of differentiated B-cell function. Endocrinology 123 834-840. (doi:10.1210/endo-123-2-834)

Kohn AD, Summers SA, Birnbaum MJ \& Roth RA 1996 Expression of a constitutively active Akt Ser/Thr kinase in 3T3-L1 adipocytes stimulates glucose uptake and glucose transporter 4 translocation. Journal of Biological Chemistry 271 31372-31378. (doi:10.1074/jbc.271. 49.31372)

Kruszynska YT, Worrall DS, Ofrecio J, Frias JP, Macaraeg G \& Olefsky JM 2002 Fatty acid-induced insulin resistance: decreased muscle PI3K activation but unchanged Akt phosphorylation. Journal of Clinical Endocrinology and Metabolism 87 226-234. (doi:10.1210/jcem.87.1. 8187)

Kulas DT, Zhang WR, Goldstein BJ, Furlanetto RW \& Mooney RA 1995 Insulin receptor signaling is augmented by antisense inhibition of the protein tyrosine phosphatase LAR. Journal of Biological Chemistry $\mathbf{2 7 0}$ 2435-2438. (doi:10.1074/jbc.270.6.2435)

Li X, Monks B, Ge Q \& Birnbaum MJ 2007 Akt/PKB regulates hepatic metabolism by directly inhibiting PGC- $1 \alpha$ transcription coactivator. Nature 447 1012-1016. (doi:10.1038/nature05861) http://joe.endocrinology-journals.org DOI: 10.1530/JOE-14-0501
() 2015 Society for Endocrinology Printed in Great Britain 
Matthaei S, Stumvoll M, Kellerer M \& Häring HU 2000 Pathophysiology and pharmacological treatment of insulin resistance. Endocrine Reviews 21 585-618. (doi:10.1210/edrv.21.6.0413)

Posner BI, Faure R, Burgess JW, Bevan AP, Lachance D, Zhang-Sun G, Fantus IG, Ng JB, Hall DA, Lum BS et al. 1994 Peroxovanadium compounds. A new class of potent phosphotyrosine phosphatase inhibitors which are insulin mimetics. Journal of Biological Chemistry $2694596-4604$.

Puigserver P, Rhee J, Donovan J, Walkey CJ, Yoon JC, Oriente F, Kitamura Y, Altomonte J, Dong H, Accili D et al. 2003 Insulin-regulated hepatic gluconeogenesis through FOXO1-PGC-1 $\alpha$ interaction. Nature $\mathbf{4 2 3}$ 550-555. (doi:10.1038/nature01667)

Roesler WJ \& Khandelwal RL 1985 Diurnal variations in the activities of the glycogen metabolizing enzymes in mouse liver. International Journal of Biochemistry 17 81-85. (doi:10.1016/0020-711X(85)90089-8)

Ruderman NB, Cacicedo JM, Itani S, Yagihashi N, Saha AK, Ye JM, Chen K, Zou M, Carling D, Boden G et al. 2003 Malonyl-CoA and AMP-activated protein kinase (AMPK): possible links between insulin resistance in muscle and early endothelial cell damage in diabetes. Biochemical Society Transactions 31 202-206. (doi:10.1042/BST0310202)

Ruff SJ, Chen K \& Cohen S 1997 Peroxovanadate induces tyrosine phosphorylation of multiple signaling proteins in mouse liver and kidney. Journal of Biological Chemistry 272 1263-1267. (doi:10.1074/jbc. 272.2.1263)

Shao J, Yamashita H, Qiao L \& Friedman JE 2000 Decreased Akt kinase activity and insulin resistance in C57BL/KsJ-Leprdb/db mice. Journal of Endocrinology 167 107-115. (doi:10.1677/joe.0.1670107)

Stephens JM, Lee J \& Pilch PF 1997 Tumor necrosis factor-alpha-induced insulin resistance in 3T3-L1 adipocytes is accompanied by a loss of insulin receptor substrate-1 and GLUT4 expression without a loss of insulin receptor-mediated signal transduction. Journal of Biological Chemistry 272 971-976. (doi:10.1074/jbc.272.2.971)

Takahashi K, Yamada T, Tsukita S, Kaneko K, Shirai Y, Munakata Y, Ishigaki Y, Imai J, Uno K, Hasegawa Y et al. 2012 Chronic mild stress alters circadian expressions of molecular clock genes in the liver. American Journal of Physiology. Endocrinology and Metabolism 304 E301-E309. (doi:10.1152/ajpendo.00388.2012)
Wang Q, Somwar R, Bilan PJ, Liu Z, Jin J, Woodgett JR \& Klip A 1999 Protein kinase B/Akt participates in GLUT4 translocation by insulin in L6 myoblasts. Molecular and Cellular Biology 19 4008-4018.

Ward H, Baldwin D, Wang T, Warner H, Seymour K, Marquardt C, McFalls E \& Foker JE 1998 Ion-exchange column chromatographic method for assaying purine metabolic pathway enzymes. Journal of Chromatography. B, Biomedical Sciences and Applications 707 295-300. (doi:10.1016/S0378-4347(97)00577-X)

Weisman GA, Lustig KD, Lane E, Huang NN, Belzer I \& Friedberg I 1988 Growth inhibition of transformed mouse fibroblasts by adenine nucleotides occurs via generation of extracellular adenosine. Journal of Biological Chemistry 263 12367-12372.

Whiteman EL, Cho H \& Birnbaum MJ 2002 Role of Akt/protein kinase B in metabolism. Trends in Endocrinology and Metabolism 13 444-451. (doi:10.1016/S1043-2760(02)00662-8)

Winder WW \& Hardie DG 1999 AMP-activated protein kinase, a metabolic master switch: possible roles in type 2 diabetes. American Journal of Physiology 277 E1-E10.

Xu E, Schwab M \& Marette A 2014 Role of protein tyrosine phosphatases in the modulation of insulin signaling and their implication in the pathogenesis of obesity-linked insulin resistance. Reviews in Endocrine \& Metabolic Disorders 15 79-97. (doi:10.1007/s11154-013-9282-4)

Yoon JC, Puigserver P, Chen G, Donovan J, Wu Z, Rhee J, Adelmant G, Stafford J, Kahn CR, Granner DK et al. 2001 Control of hepatic gluconeogenesis through the transcriptional coactivator PGC-1. Nature 413 131-138. (doi:10.1038/35093050)

Zhang J, Kaasik K, Blackburn MR \& Lee CC 2006 Constant darkness is a circadian metabolic signal in mammals. Nature 439 340-343. (doi:10.1038/nature04368)

Zhang Y, Wang Z, Zhao Y, Zhao M, Wang S, Hua Z \& Zhang J 2012 The plasma $5^{\prime}$-AMP acts as a potential upstream regulator of hyperglycemia in type 2 diabetic mice. American Journal of Physiology. Endocrinology and Metabolism 302 E325-E333. (doi:10.1152/ajpendo. 00424.2011)

Zhou YP, Cockburn BN, Pugh W \& Polonsky KS 1999 Basal insulin hypersecretion in insulin-resistant Zucker diabetic and Zucker fatty rats: role of enhanced fuel metabolism. Metabolism 48 857-864. (doi:10.1016/S0026-0495(99)90219-6)

Received in final form 22 November 2014

Accepted 15 December 2014

Accepted Preprint published online 15 December 2014
() 2015 Society for Endocrinology Printed in Great Britain 